Pacific Journal of Mathematics

INTERPOLATION SETS FOR UNIFORM ALGEBRAS 


\section{INTERPOLATION SETS FOR UNIFORM ALGEBRAS}

\section{ARne Stray}

Let $A$ be a uniform algebra on a compact Hausdorff space $X$ and let $E \subset X$ be a closed subset which is a $G_{j}$. Denote by $B_{E}$ all functions on $X \backslash E$ which are uniform limits on compact subsets of $X \backslash E$ of bounded sequences from $A$.

It is proved that a relatively closed subset $S$ of $X \backslash E$ is an interpolation set and an intersection of peak sets for $B_{E}$ if and only if each compact subset of $S$ has the same property w. r. t. $A$. In some special cases the interpolation sets for $B_{E}$ are characterized in a similar way. A method for constructing infinite interpolation sets for $A$ and $B_{E}$ whenever $x \in E$ is a peak point for $A$ in the closure of $X \backslash\{x\}$, is presented.

With $X$ as above let $S \subset X$ be a topological subspace. Then $C_{b}(S)$ denotes all bounded continuous complexvalued functions on $S$ and we put $\|f\|=\sup \{|f(x)|: x \in S\}$ if $f \in C_{b}(S)$.

A subset $S$ of $X \backslash E$ closed in the relative topology is called an interpolation set for $B_{E}$ if any $f \in C_{b}(S)$ has an extension to $X \backslash E$ which belongs to $B_{E}$. If there exists $f \in B_{E}$ such that $f=1$ on $S$ and $|f|<1$ on $(X \backslash E) \backslash S$, we call $S$ a peak set for $B_{E}$. If $S$ has both this properties it is called a peak interpolation set for $B_{E}$. Peak and interpolation sets for $A$ are defined in the same way.

It is easy to see that $B_{E}$ is a Banach algebra with the norm $N(f)=\inf \left\{\sup _{n}\left\|f_{n}\right\|:\left\{f_{n}\right\} \subset A, f_{n} \rightarrow f\right.$ uniformly on compact subsets of $X \backslash E\}$. It is an interesting problem in itself when this norm coincides with sup norm on $X \backslash E$.

In case $X=\{z:|z| \leqq 1\}$ and $A$ is the classical disc algebra of all continuous functions on $X$ which are analytic in $D=\{z:|z|<1\}$ the interpolation sets for $B_{E}$ (where $E$ is a closed subset of $\partial X$ ) are characterized by that $S \cap \partial X$ has zero linear measure and that $S \cap D$ is an interpolation set for $H^{\infty}(D)$, the algebra of all bounded analytic functions on $D$. This result was obtained in [8] by E. A. Heard and J. H. Wells.

Their work has been generalized in different ways. Various authors have considered more general subsets $E$ of $\{z:|z| \leqq 1\}$ and more general algebras of analytic functions. ([2], [3], [4], [6], [9] and [10]).

In this note we wish to generalize the results of Heard and Wells to the setting of uniform algebras. We start with an extension of Theorem 2 in [8]. 
THEOREM 1. Let $S \subset X \backslash E$ be closed in the relative topology. Assume $X$ is the maximal ideal space of $A$. The following statements are equivalent:

(i) Given $g \in C_{b}(S), \varepsilon>0$ and an open set $U \supset S$, there exists $f \in B_{E}$ such that $f=g$ on $S,\|f\|=\|g\|,|f|<\varepsilon$ on $(X \backslash E) \backslash U$ and $N(f) \leqq\|g\|(1+\varepsilon)$.

(ii) There exists a constant $M$ such that if $g \in C_{b}(S), \varepsilon>0$ and $U \supset S$ is open we can find $f \in B_{E}$ such that $f=g$ on $S,|f|<\varepsilon$ on $(X \backslash E) \backslash U$ and $N(f) \leqq M\|g\|$.

(iii) Each compact subset of $S$ is an interpolation set and an intersection of peak sets for $A$.

Proof. That (i) $\Rightarrow$ (ii) is trivial.

(ii) $\Rightarrow$ (iii). Choose $g \in C(K)$ with $\|g\|=1$.

Let $K \subset S$ be compact, $U$ and $W$ open sets such that $K \subset W \subset$ $\bar{W} \subset U \subset \bar{U} \subset X \backslash E$ and choose $\varepsilon>0$. By hypothesis there exists $g_{1} \in B_{E}$ equal to $g$ on $K$ such that $\left|g_{1}\right|<\varepsilon / 2$ on $\bar{U} \backslash W$ and $N\left(g_{1}\right) \leqq M$.

Hence we can find $g_{2} \in A$ with $\left\|g_{2}\right\| \leqq M,\left|g-g_{2}\right|<\varepsilon$ on $K,\left|g_{2}\right|<\varepsilon$ on $\bar{U} \backslash W$ and $\left\|g_{2}\right\| \leqq M$. By ([8], Lemma 2) applied to the restriction map $B_{E} \rightarrow C(K)$ we get that any $g \in C(K)$ we get that any $g \in C(K)$ has an extension $f$ to $X$ such that $f \in A,\|f\| \leqq M /(1-\varepsilon)$ and $|f|<$ $\varepsilon /(1-\varepsilon)$ on $\bar{U} / W$. Essentially by Bishops " $1 / 4-3 / 4$-Theorem" (See [5], Th. 11.1 p. 52) we can use what is proved until now to find a compact set $K_{1}$ and $f_{1} \in A$ such that $f_{1}=1$ on $K_{1},\left|f_{1}\right|<1$ on $U \backslash K_{1}$ and $K \subset K_{1} \subset W$. By "Rossis Local Peak Set Theorem" ([5], p. 91) $K_{1}$ is a peak set for $A$ and (iii) is proved.

It remains to prove (iii) $\Rightarrow$ (i). We only indicate how to modify our proof of Lemma 2.1 in [10] to apply to the present situation. As in that lemma we construct a sequence $\left\{f_{n}\right\}_{n=1}^{\infty} \subset A$ with the properties listed there. Let $t \in\langle 0,1\rangle$. The sum $\sum_{1}^{\infty} f_{n}=f \in B_{E}$ and the proof of Lemma 2.1 gives (i) if we can show that $N(f) \leqq 1+t$. This is obtained by constructing $\left\{f_{n}\right\}$ such that $\left\|f_{n}+f_{n+1}\right\| \leqq 1+1 / 2 \cdot t$ for $n=0,1, \cdots$.

This can be obtained if when constructing $f_{n+1}$ we arrange it so that $\left|f_{n}+f_{n+1}\right|=\left|f_{n}\right|+\left|f_{n+1}\right|$ on $K_{n+1} \cup K_{n+2}\left(K_{n+1}, K_{n+2}\right.$ as in [10]) and then if needed, modify $f_{n+1}$ to $h \cdot f_{n+1}$ where $h \in A$ equals $1=\|h\|$ on $K_{n+1} \cup K_{n+2} \cup K_{n+3}$, is small where $\left|f_{n}+f_{n+1}\right|$ may be large and has a small imaginary part.

We now state a lemma which is due to A. M. Davie:

LEMMA 1. There exists a sequence $\left\{Q_{k}\right\}_{k=1}^{\infty}$ of polynomials with the following properties:

(1) $\sum_{1}^{n} Q_{k}(z) \rightarrow 1$ uniformly on compact subset of $\{z:|z|<1\}$

(2) $Q_{k}(1)=0$ for $k=1,2, \cdots$ and $\sum_{1}^{\infty}\left|Q_{k}(z)\right| \leqq 3$ if $|z| \leqq 1$. 
For a construction of $\left\{Q_{k}\right\}$ see the proof of Theorem 2.4 in [1].

We now have:

THEOREM 2. Let $E$ be a peak set for $A$ and let $S \subset X \backslash E$ be closed in the relative topology. The following statements are equivalent:

(i) $S$ is an interpolation set for $B_{E}$.

(ii) There exists $M>0$ such that if $K \subset S$ is compact and $g \in$ $C(K)$ we can find $f \in A$ equal to $g$ an $K$ and with $\|f\| \leqq M\|g\|$.

Proof. (ii) follows from (i) as in the first part of the proof that (ii) $\Rightarrow$ (iii) in Theorem 1. For the converse an argument used by Davie in [1] works: Choose $h \in A$ peaking on $E$ and put $E_{k}=S \cap$ $\left\{x:\left|Q_{k} \circ h(x)\right| \geqq \varepsilon \cdot h^{-k}\right\}$ where $\varepsilon>0$ is given in advance. Let $g \in C_{b}(S)$ with $\|g\|=1$. Choose by hypothesis $g_{k} \in A$ equal to $g$ on $E_{k}$ with $\left\|g_{k}\right\| \leqq M$ and put $G=\sum_{k=1}^{\infty}\left(Q_{k} \circ h\right) \cdot g_{k}$. Then by Lemma $1 G \in B_{E}$, $\|G\| \leqq 3 M$ and if $x \in S$ we have

$$
\begin{aligned}
|G(x)-g(x)| & =\left|\sum_{1}^{\infty}\left(g_{k}(x)-g(x)\right) Q_{k} \circ f(x)\right| \\
& \leqq \sum_{1}^{\infty} \in 2^{-k}=\varepsilon .
\end{aligned}
$$

By Lemma 2 in [8] (i) follows.

The hypothesis that $E$ is a peak set for $A$ seems unnecessary, but we needed it to apply Lemma 1 . It would be of interest to get some examples where Theorem 2 holds without assuming $E$ to be a peak set.

A case which deserves investigation is when $A$ is an algebra of generalized analytic functions ([5], Ch VII) viewed as a uniform algebra on its maximal ideal space. Then $B_{E}$ is very easy to describe whenever $E$ is a closed subset of the Silov boundary of $A$. In particular the norm $N(f)$ coincides with sup norm on $X \backslash E$ in this case.

We want to give two examples where a more detailed description of the interpolation sets for $B_{E}$ can be given.

(a) Let $U \subset C^{n}$ be a strictly pseudoconvex domain with $C^{2}$ boundary and let $X$ be the closure of $U$. Let $A$ be the algebra $A(U)=$ $\left\{f \in C(X):\left.f\right|_{U}\right.$ is analytic $\}$.

In this case Theorem 2 is valid if $E$ is any closed subset $\partial U$ and the interpolation set $S$ can then also be characterized by the following:

(I): Each compact subset of $S \cap \partial U$ is a peak interpolation set for $A$,

and

(II): $S \cap U$ is an interpolation set for $H^{\infty}(U)$, the algebra of all bounded analytic functions in $U$. 
For a proof of this note that (i) $\Rightarrow$ (ii) in Theorem 2 holds whenever $E$ is a closed $G_{\delta}$. That (ii) $\Rightarrow$ (II) is a simple normal family argument and I also follows from (ii) by a result of N. H. Varopoulos [11] and since each $x \in \partial U$ is a peak point for $A(U)$ in this special case.

To obtain (i) from (I) and (II) one can argue as in the proof of Theorem 2.2 in [10]. To use that proof one needs an approximation result similar to Theorem 2.1 in [10]. This nontrivial result is contained in a recent work of R. M. Range [9].

(b) Assume $A$ is a Dirichlet algebra on its Šlov boundary $Y$.

Let $E$ be a peak interpolation set for $A$ and let $S \subset X \backslash E$ be closed in the relative topology and assume $S \backslash Y$ countable. Then one can prove that $S$ is an interpolation set for $B_{E}$ if each compact subset of $S \cap Y$ is an interpolation set for $A$ and if for some constant $C$ the following result holds: If $P$ is a nontrivial Gleason part for $A$ and $S \cap P=z_{1}, z_{2}, \cdots$ and $\alpha_{1}, \alpha_{2}, \cdots$ are numbers such that $\left|\alpha_{k}\right| \leqq 1$ for $k=1,2, \cdots$ there exists $f \in H^{\infty}(P)$ such that $f\left(z_{k}\right)=\alpha_{k}$ for $k=1,2, \cdots$ and $|f| \leqq C$ on $P$. (For the necessary definitions see [5] on page 34, 142 and 161).

Using this hypothesis and the Wermer-Glicksberg decomposition ([5], Thm. 7.11, p. 45) we can prove that $S \cup E$ is an interpolation set for $A$. This is done in the same way as Glicksberg proves Theorem 4.1 in [7]. But then $S$ is an interpolation set for $B_{E}$ by Theorem 2.

In [8] Heard and Wells described an explicit method for constructing infinite interpolation sets for $B_{\{x\}}$ if $x \in X$ is a non-isolated peak point for $A$. Their method didn't depend on Carlesons characterization of the interpolating sequences for $H^{\infty}(D)$.

We indicate here how the polynomials $\left\{Q_{k}\right\}$ can be used for a similar construction avoiding an unnecessary hypothesis about connectedness which Heard and Wells assumed. ([8], Theorem 3).

Theorem 3. Let $x \in X$ be a peak point for $A$ and $P \subset X \backslash\{x\} a$ set which contains $x$ in its closure. Then an infinite interpolation set for $B_{\{x\}}$ contained in $P$ can be constructed.

Proof. Choose $\varepsilon>0$ and $f \in A$ peaking at $x$. For $k=1,2, \cdots$ choose numbers $n_{k}$ and $m_{k}$ such that $n_{k}<m_{k}<n_{k+1}$ and put $H_{k}=$ $\sum_{n_{k}}^{m_{k}} Q_{j} \circ f$. Using Lemma 1 it is easy to see that we can arrange it such that the sets $E_{k}=\left\{x:\left|H_{k}(x)\right| \geqq \varepsilon 2^{-k}\right\}$ and

$$
B_{k}=P \cap\left\{x:\left|H_{k}(x)-1\right|<\varepsilon 2^{-k}\right\}
$$

are nonempty for $k=1,2, \cdots$ and that $E_{i} \cap E_{j}=\varnothing$ if $i \neq j$. 
If we choose $x_{k} \in B_{k}$ for $k=1,2, \cdots$ then $S=\left\{x_{k}\right\}_{k=1}^{\infty}$ is an interpolation set for $B_{\{x\}}$. For if $g \in C_{b}(S)$ and we put $G=\sum_{1}^{\infty} g\left(x_{k}\right) H_{k}$ then $G \in B_{\{x\}},\|G\| \leqq 3\|g\|$ by Lemma 1 and $|G-g|<\varepsilon\|g\|$ on $S$.

Comments on Theorem 2:

We want to point out that the hypothesis that $E$ be a peak set cannot be omitted. If $A$ is any uniform algebra for which there exists an infinite interpolation set $F$ not meeting the Šilov boundary, one obtains a counterexample by taking $E$ to be a limit point of $F$ and $S=F \backslash E$. For an example of such an algebera $A$ we refer to Theorem 2.8. in [1]. On the other hand A. M. Davie has recently proved (private communication) that in case $A$ is the algebra $R(X)$ and $X$ is a compact plane set, Theorem 2 is valid without assuming $E$ to be a peak set.

\section{REFERENCES}

1. A. M. Davie, Linear extension operators for spaces and algebras of functions, Amer. J. Math., 94 (1972), 156-172.

2. A. M. Davie and A. Stray, Interpolation sets for analytic functions, (To appear in Pacific J. of Math.).

3. A. M. Davie and B. K. Øksendal, Peak interpolation sets for some algebras of analytic functions, (To appear).

4. J. Detraz, Algebres de fonctions analytique dans le disque. Ann. Sci. Ecole Norm. Sup. 3 (1970) 313-352.

5. T. W. Gamelin, Uniform Algebras, Prentice Hall, Englewood Cliffs, N. J. 1969.

6. T. W. Gamelin and J. Garnett, Uniform approximation to bounded analytic functions, (To appear in the volume in honor of Professor González Dominguez, Revista de la Union Matematica Argentina).

7. I. Glicksberg, Dominant representing measures and rational approximation, T.A.M.S., 130 (1968), 425-462.

8. E. A. Heard and J. H. Wells, An interpolation problem for subalgebras of $H^{\infty}$, Pacific J. Math., 28, (1969), 543-553.

9. R. M. Range, Approximation to bounded holomorphic functions on strictly pseudoconvex domains, (To appear).

10. A. Stray, Approximation and interpolation, Pacific J. Math., 40 (1972), 463-475.

11. N. T. Varopoulos, Ensembles pics et ensembles d'interpolation pour les algébres uniformes, C. R. Acad. Sci. Paris, Serie A, 272 (1971), 592.

Received July 26, 1971 and in revised form September 22, 1971.

UNIVERSITY OF OSLO 



\section{PACIFIC JOURNAL OF MATHEMATICS}

\section{EDITORS}

\author{
H. SAMELSON \\ Stanford University \\ Stanford, California 94305 \\ C. R. HOBBY \\ University of Washington \\ Seattle, Washington 98105
}

\author{
J. DugundJI \\ Department of Mathematics \\ University of Southern California \\ Los Angeles, California 90007
}

\author{
RICHARD ARENS \\ University of California \\ Los Angeles, California 90024
}

\section{ASSOCIATE EDITORS}
E. F. BECKENBACH
B. H. NeumanN
F. WOLF
K. YoSHIDA

\section{SUPPORTING INSTITUTIONS}

\author{
UNIVERSITY OF BRITISH COLUMBIA \\ CALIFORNIA INSTITUTE OF TECHNOLOGY \\ UNIVERSITY OF CALIFORNIA \\ MONTANA STATE UNIVERSITY \\ UNIVERSITY OF NEVADA \\ NEW MEXICO STATE UNIVERSITY \\ OREGON STATE UNIVERSITY \\ UNIVERSITY OF OREGON \\ OSAKA UNIVERSITY
}

\author{
UNIVERSITY OF SOUTHERN CALIFORNIA \\ STANFORD UNIVERSITY \\ UNIVERSITY OF TOKYO \\ UNIVERSITY OF UTAH \\ WASHINGTON STATE UNIVERSITY \\ UNIVERSITY OF WASHINGTON \\ $* * * *$
$*$
AMERICAN MATHEMATICAL SOCIETY
NAVAL WEAPONS CENTER
}

The Supporting Institutions listed above contribute to the cost of publication of this Journal, but they are not owners or publishers and have no responsibility for its content or policies.

Mathematical papers intended for publication in the Pacific Journal of Mathematics should be in typed form or offset-reproduced, (not dittoed), double spaced with large margins. Underline Greek letters in red, German in green, and script in blue. The first paragraph or two must be capable of being used separately as a synopsis of the entire paper. The editorial "we" must not be used in the synopsis, and items of the bibliography should not be cited there unless absolutely necessary, in which case they must be identified by author and Journal, rather than by item number. Manuscripts, in duplicate if possible, may be sent to any one of the four editors. Please classify according to the scheme of Math. Rev. Index to Vol. 39. All other communications to the editors should be addressed to the managing editor, Richard Arens, University of California, Los Angeles, California, 90024.

50 reprints are provided free for each article; additional copies may be obtained at cost in multiples of 50 .

The Pacific Journal of Mathematics is published monthly. Effective with Volume 16 the price per volume (3 numbers) is $\$ 8.00$; single issues, $\$ 3.00$. Special price for current issues to individual faculty members of supporting institutions and to individual members of the American Mathematical Society: $\$ 4.00$ per volume; single issues $\$ 1.50$. Back numbers are available.

Subscriptions, orders for back numbers, and changes of address should be sent to Pacific Journal of Mathematics, 103 Highland Boulevard, Berkeley, California, 94708.

PUBLISHED BY PACIFIC JOURNAL OF MATHEMATICS, A NON-PROFIT CORPORATION

Printed at Kokusai Bunken Insatsusha (International Academic Printing Co., Ltd.), 270, 3-chome Totsuka-cho, Shinjuku-ku, Tokyo 160, Japan. 


\section{Pacific Journal of Mathematics}

\section{Vol. 43, No. 2 \\ April, 1972}

Arne P. Baartz and Gary Glenn Miller, Souslin's conjecture as a problem on the real line....................................... 277

Joseph Barback, On solutions in the regressive isols ............... 283

Barry H. Dayton, Homotopy and algebraic K-theory ................ 297

William Richard Derrick, Weighted convergence in length ............ 307

M. V. Deshpande and N. E. Joshi, Collectively compact and semi-compact sets of linear operators in topological vector spaces ............. 317

Samuel Ebenstein, Some $H^{p}$ spaces which are uncomplemented in $L^{p} \ldots . .327$

David Fremlin, On the completion of locally solid vector lattices ......... 341

Herbert Paul Halpern, Essential central spectrum and range for elements of

a von Neumann algebra............................... 349

G. D. Johnson, Superadditivity intervals and Boas' test ............. 381

Norman Lloyd Johnson, Derivation in infinite planes . . . . . . . . . . . 387

V. M. Klassen, The disappearing closed set property .............. 403

B. Kuttner and B. N. Sahney, On the absolute matrix summability of Fourier series ........................................... 407

George Maxwell, Algebras of normal matrices................... 421

Kelly Denis McKennon, Multipliers of type $(p, p) \ldots \ldots \ldots \ldots \ldots \ldots . . \ldots 29$

James Miller, Sequences of quasi-subordinate functions ............. 437

Leonhard Miller, The Hasse-Witt-matrix of special projective varieties ..... 443

Michael Cannon Mooney, A theorem on bounded analytic functions ...... 457

M. Ann Piech, Differential equations on abstract Wiener space .......... 465

Robert Piziak, Sesquilinear forms in infinite dimensions ............. 475

Muril Lynn Robertson, The equation $y^{\prime}(t)=F(t, y(g(t))) \ldots \ldots \ldots \ldots .483$

Leland Edward Rogers, Continua in which only semi-aposyndetic

subcontinua separate ............................... 493

Linda Preiss Rothschild, Bi-invariant pseudo-local operators on Lie

groups ...................................... 503

Raymond Earl Smithson and L. E. Ward, The fixed point property for

arcwise connected spaces: a correction ...................... 511

Linda Ruth Sons, Zeros of sums of series with Hadamard gaps .......... 515

Arne Stray, Interpolation sets for uniform algebras............... 525

Alessandro Figà-Talamanca and John Frederick Price, Applications of random Fourier series over compact groups to Fourier multipliers .. 